Series: Disasters and geopolitics: Implications for nursing ORIGINAL ARTICLE

\title{
Nepal's earthquake: The country's struggles with effective public health response amidst international politics and cultural conflicts
}

\author{
Reshma SHRESTHA \\ University of Virginia School of Nursing, Charlottesville, Virginia, USA
}

\begin{abstract}
Aim: This paper examines the interplay of geopolitical and humanitarian responses to the 2015 earthquake in Nepal, a devastating 7.9-magnitude earthquake that resulted in nearly 9,000 deaths and 22,000 injuries.

Methods: Historical methodology used primary sources from the World Health Organization, USAID, and the voices of nurses who responded on the ground. Secondary sources included disaster nursing and international relations literature.

Results: Much of the disaster response involved local Nepali people who worked to take care of their own. Nurses and other aid workers from various countries also treated patients and distributed sufficient food and supplies.

Conclusions: Tensions over nation-state boundaries affected the response, but in the end, relief was a joint effort, with international, national, and local organizations teaming up to provide health care.
\end{abstract}

Key words: disaster, earthquake, international relations, Nepal, political response

\section{INTRODUCTION}

On April 25, 2015, a devastating 7.9-magnitude earthquake hit Nepal affecting its capital, Kathmandu, the largest populated city in the country. Remote rural areas also experienced extensive damage. According to the World Health Organization (WHO), nearly 9,000 deaths occurred, and another 22,000 people were injured (BBC News, 2015; United States Agency for International Development (USAID), 2015, Fact Sheet \#2; World Health Organization (WHO, 2015). It was the worst earthquake to hit Nepal in 80 years, prompting the Nepali government to declare a state of emergency. Government leaders quickly requested international assistance. Some of the first responders were the locals in the area who worked with rescue teams to find survivors. Because Nepal is a country with strategic significance in Asia, tensions over nation-state boundaries affected the re-

Correspondence: Reshma Shrestha. Email: rs8er@virginia.edu Received 28 September 2017; accepted 1 October 2017; J-STAGE advance published 8 February 2018. sponse to the earthquake.

Nepal is a land-locked country that needs connections to waterways and railroads in both India and China (People's Republic of China). Tibet, for example, which borders Nepal, is claimed by China, and it includes the sources of China's Yellow, Yangtze, and Mekong Rivers (Marshall, 2015). For border security, both China and India have vied for influence and power in Nepal in recent years, and representatives from both countries were quick to respond to the earthquake (Biswas, 2015). The Indian government launched an extensive humanitarian relief and rescue operation by deploying 10 national disaster response teams. These included medical professionals, an engineering task force, and emergency relief commodities such as medicines, safe drinking water, and blankets. Yet conflicts over the Indo-Nepali border had recently caused much tension, and the unrest meant supplies from the Indian government were slow to arrive at the devastated areas. The Chinese Government also responded by sending search-and-rescue teams with dog sniffers and medical equipment, and donated more than US\$3.2 million in the first few days. China pledged 
even more money for post-earthquake reconstruction that included upgrading Nepal-China road links (Baral, 2017). As both China and India vied for control, the Nepali Government had to tread carefully regarding how to accept aid. Thus, foreign policy played a large role in the lives of Nepali people after the earthquake.

\section{INTERNATIONAL RESPONSE}

The earthquake and aftershocks damaged more than 1,000 health facilities, and 5 million people did not have access to healthcare services (USAID, 2015, Fact Sheet \#18). One of the largest private hospitals in Nepal, Grande International Hospital, for example, had become completely inoperable. Thus, medical tents, medications, surgical equipment, and other medical supplies were required. In addition to responses by India and China, various countries such as Thailand, Pakistan, the United Kingdom, Australia, Israel, the United States and many others contributed to rescue and rebuilding efforts (WHO, 2015). Pakistan, for example, sent supplies, search-andrescue teams, and medical teams (USAID, 2015, Fact Sheet \#2). Other groups included the United Nations Development Program, the Red Cross, and Oxfam (Symmes, 2016).

Nepal needed the international assistance because of the depletion of local supplies and overcrowding in hospitals. The WHO collaborated with the Ministry of Health and the local population to assess the injured. The government, with the help of the WHO, also developed an Early Warning and Response System to detect epidemic-prone diseases (USAID, 2015, Fact Sheet \#12). The United Nations International Children's Emergency Fund (UNICEF) worked with the Ministry of Urban Development to create Water, Sanitation, and Hygiene (WASH) clusters to map areas needing this type of help (USAID, 2015, Fact Sheet \#6). Various nongovernmental organizations also collaborated to provide health care. International relief organizations such as Médecins Sans Frontières, or Doctors Without Borders, participated tremendously in disease prevention, medical attention, and other rescue efforts.

Monsoon rains and multiple aftershocks led to reports of respiratory infections, mosquito-borne diseases, and diarrheal cases (USAID, 2015, Fact Sheet \#7). As the WASH cluster in Nepal identified the most affected areas and collaborated with local officials in those districts, it was hard for the WASH cluster to reach certain areas due to the rains. In addition to disease surveillance, the WHO worked with the Nepali Government to promote public health messages to reduce the risk of disease outbreaks.
Other relief organizations distributed hygiene kits, safe drinking water, and water treatment supplies. Along with water-borne diseases, WHO assessments found that more than 3,000 children suffered from acute malnutrition, and thus 30 WHO centers treated those survivors (WHO, 2015).

\section{NURSES ON THE GROUND}

Significantly, local staffing was also available in the form of competent doctors and nurses, and many were prepared to work immediately after the earthquake. Joe Niemczura, a registered nurse and educator in Nepal, had been teaching Nepali nurses and physicians advanced life support skills since 2011, and 800 of his former students were in the region when the earthquake hit. He noted, "In my classes, I joke about how in emergency situations we have to become zombies-overcome the shock of an emergency and just apply what we know automatically." He explained that in Nepal,

There's a culture of waiting for permission from an elder or superior before acting. For a professional person [like a nurse], that mind-set is a problem.... If you survive a disaster, you are going to have to be ready to use your skills.... Every nurse, no matter what their clinical practice is or where they live, has to realize the job they have in society. That's the lesson. There's no international person who is going to come to any area soon enough, so the people who are there have to be ready to do what they do (Niemczuraz, quoted in Schwartz, 2015). He was pleased his former students could do just that.

Emma Pedley worked as a nurse with Doctors Without Borders and flew in by helicopter to remote villages cut off from access to care (Schofield, 2015). The relief agency had preplanned everything about her journey to Nepal, according to a statement she made later, and she felt very prepared for any emergency. Pedley had received a diploma in tropical nursing at the United Kingdom's London School of Hygiene and Tropical Medicine in 2007. She also had taken several courses in public health as part of a Master's program. She had disaster relief experiences in several areas, and she had already conducted fieldwork in Nepal. Thus, she was familiar with how health care worked in that country. Her job included distributing health kits, vaccinating children and adults against diseases such as tetanus, and providing acute care. She recalled, “It wasn't straight in doing trauma surgery and things like that because Nepal has an okay health system, a decent education system, doctors and nurses and functioning hospitals. With the hospital, 
there was no denying it, they were busy and they were overwhelmed, but they were functioning" (Schofield, 2015).

Four nurses, including Debra McQuillen, went to Nepal as part of the Scripps Health Medical Response Team from the United States. They were part of a 21-day medical mission that treated more than 2,200 patients after the earthquake. McQuillen noted that the nurses awakened along with the villagers, typically at 4:30 a.m., and ran the clinic until 6:30 p.m. Nurses mostly encountered infected lacerations that resulted from delay in care, and they treated people with stomach illnesses, infections, and insomnia. They also worked with Nepali doctors who helped them understand the problems and cultures of the villagers (Cabrera, Cavanaugh, \& Pico, 2015).

Both Pedley and McQuillen reported a frequency of survivors suffering from psychological trauma. McQuillen noted that, after the many aftershocks that occurred, they would hear loud screams from the people in the villages because they recalled the trauma from the previous earthquake. Pedley observed that, as she was treating the villagers, they received psychological counselling in groups, which provided the villager with significant relief. Psychological care indeed was an important factor in treatment efforts (Cabrera et al., 2015; Schofield, 2015).

Rebuilding efforts after the earthquake were slow due to bureaucratic red tape, which led to anger and frustration among many of the people. At the same time, nurses learned that it was important to understand the culture of local populations wherever they worked. Nurse Pedley already had experience in Nepal, and it was easier for her to understand customs and healthcare practices (Schofield, 2015). Nurse Niemczura had worked in Nepal for several years and knew that Nepali customs were vastly different to that of Western countries. It also helped to know the language and dietary preferences (rice and lentils) and to understand that it was not the policy of hospitals to provide food for patients. Nurses also had to prepare for caste differences in Nepal (Schwartz, 2015).

Although many people wanted to go to the region to help, some did not have the special training needed. Claire Bennett, who had lived in Nepal for many years, made a plea to avoid rushing into Nepal as volunteers; these untrained but well-intentioned personnel could slow down aid efforts. Rather, she recommended that people donate to organizations such as Doctors Without Borders, which had qualified staff. At the same time, through local, national, and international efforts, professionals with needed skills were available, at least to provide some support (Bennet, 2015).

\section{CONCLUSION}

Humanitarian concerns are at the root of many disaster responses, and they were at work after the earthquake in Nepal. At the same time, nation states and non-state actors have their own incentives for responding (Ferris, 2010). This does not deny that, through the resilience of the Nepali people and help from local, national, and international agencies, Nepal tried to recover and take care of its people. Although tensions over nation-state boundaries affected the response, nurses and other aid workers from various countries worked tirelessly to get to all the villages and treat patients and distribute sufficient food and supplies. Relief was a joint effort with international, national, and local organizations teaming up to provide health care; but people are still displaced and recovery must take place one step at a time.

This is historical research that relied only on public data; therefore, no Institutional Review Board was required.

\section{REFERENCES}

Baral, B. (2017, February 21). After the 'Blockade': China's Push into Nepal. The Diplomat. [Cited 25 April 2017]. Available from URL: http://thediplomat.com/2017/02/after-theblockade-chinas-push-into-nepal/

BBC News. (2015, May 15). Nepal earthquakes: Devastation in maps and images. [CITED 25 April 2017]. Available from URL: http://www.bbc.com/news/world-asia-32479909

Bennett, C. (2015, April 27). Don't rush to Nepal to help. Read this first. The Guardian. [Cited 25 April 2017]. Available from URL: https://www.theguardian.com/commentisfree/2015/apr/ 27/earthquake-nepal-dont-rush-help-volunteers-aid?CMP= share_btn_tw

Biswas, S. (2015, April 28). Nepal earthquake: How India and China vie for influence. BBC News. [Cited 25 April 2017]. Available from URL: http://www.bbc.com/news/world-asiaindia-32492273

Cabrera, M., Cavanaugh, M., \& Pico P. (2015, May 20). Scripps nurses reflect on Nepal quake recovery efforts. KPBS News. [Cited 25 April 2017]. Available from URL: http://www. kpbs.org/news/2015/may/28/scripps-nurses-reflect-nepal/

Ferris, E. (2010). Presentation, natural disasters, conflict, and human rights: Tracing the connections. Brookings Institution Project on Internal Displacement. pp. 1-9. Washington, DC: Brookings Institute.

Marshall, T. (2015). Prisoners of geography: Ten maps that tell you everything you need to know about global politics. London: Elliott and Thompson, Ltd.

Schofield, K. H. (2015, September 17). Nepal earthquake nurse. Nursing in Practice. [Cited 25 April 2017]. Available from URL: https://www.nursinginpractice.com/article/profile-nepalearthquake-nurse 
Swartz, A. (2015). Earthquakes, Nepal, and hospital care. Medscape. [Cited April 25, 2017]. Available from URL: http://www.medscape.com/viewarticle/845673_8

Symmes, P. (2016). A year after the quake, Nepal is still a mess. [Cited 25 April 2017]. Available from URL: https://www. outsideonline.com/2086666/aftershock

United States Agency for International Development (USAID). (2015, April 27). Nepal Earthquake-Fact Sheet \#2. [Cited 25 April 2017]. Available from URL: https://www.usaid.gov/ nepal-earthquake/fy $15 /$ fs 02

United States Agency for International Development (USAID). (2015, May 1). Nepal Earthquake-Fact Sheet \#6. [Cited 25 April 2017]. Available from URL: https://www.usaid.gov/ nepal-earthquake/fy $15 /$ fs 06

United States Agency for International Development (USAID). (2015, May 3). Nepal Earthquake-Fact sheet \#7. [Cited 25
April 2017]. Available from URL: https://www.usaid.gov/ nepal-earthquake/fy15/fs07

United States Agency for International Development (USAID) (2015, May 13). Nepal Earthquake-Fact Sheet \#12. [Cited 25 April 2017]. Available from URL: https://www.usaid.gov/ nepal-earthquake/fy $15 /$ fs 12

United States Agency for International Development (USAID). (2015, May 28). Nepal Earthquake-Fact Sheet \#18. [Cited 25 April 2017]. Available from URL: https://www.usaid.gov/ nepal-earthquake/fy $15 /$ fs 18

World Health Organization (WHO). (2015). WHO coordinating the health response to Nepal Earthquake; working to prevent spread of disease. [Cited 25 April 2017]. Available from URL: http://www.who.int/mediacentre/news/releases/2015/ who-health-response-nepal/en/ 